\title{
The Impact of Transformational Leadership on Crisis Management in the Cellular Communications Sector in Jordan
}

\author{
Ethar Khalaf Ibrahim ALHumeisat ${ }^{1} \&$ Samer Abdulmajid Hazeem ALBashabsheh ${ }^{1}$ \\ ${ }^{1}$ Mutah University, Jordan \\ Correspondence: Ethar Khalaf Ibrahim ALHumeisat, Mutah University, Jordan.
}

Received: October 8, 2020

Accepted: November 9, 2020

Online Published: November 17, 2020

doi:10.5539/mas.v14n12p27

URL: https://doi.org/10.5539/mas.v14n12p27

\begin{abstract}
The current study aimed to identify the impact of transformational leadership on crisis management in the Cellular Communications sector in Jordan. This study relies on the descriptive and analytical approach for this study.

The study population includes administrators working in Zain, Orange, and Umniah companies. A Convenience non-probability sample of 100 managers was taken to distribute the study questionnaire to them.

Moreover, the study reached the following results: There is a statistically significant impact at $(\alpha \leq 0.05)$ for transformational leadership with its dimensions (ideal effect, inspirational stimulation, intellectual stimulation, individual considerations) on crisis management in Jordan cellular communications sector.

In light of the previous results, the researcher recommends the following: The necessity for the administration to use the information network security system to retrieve information before the crisis occurs. Senior management's necessity to benefit from its previous experiences to generate knowledge benefits the organization's employees - the need to create an organizational culture that promotes the useful application of transformational leadership.
\end{abstract}

Keywords: transformational leadership, leadership, crisis management, cellular communications

\section{Introduction}

Leadership is among the topics that have formed a part of human interests due to progress in science and knowledge, development in different walks of life, and change in society's concepts and values. There has become a need for leaders with a high level of experience, appropriate competence, knowledge, the ability to assume responsibility, and keep pace with all that is developed to fulfill the essential leadership role in an organization.

In light of the developments taking place in the environment, it was imperative to make changes in organizations' environments and encourage innovation and renewal. That leads to the necessity of highlighting non-traditional leadership styles and highlighting them in order to benefit from them in various organizations in the public and private sectors, and among these patterns is the transformational leadership style, where the manager is interested in this type of leadership styles in communicating the organization's message to employees clearly and encouraging them to implement it within high ethical controls and enhance respect between both parties (the manager and the employee) (Nemanich \& Keller, 2007).

Hence, leadership is of great importance for its role in every stage that crises in organizations go through, and whose departments must respond to them with a clear vision that enables them to deal with them and benefit from them in the future. Treating the crisis or making the appropriate decision regarding it (Tekin, 2014).

The study's importance lies in the fact that it focuses on transformational leadership and the importance of its application in various organizations. Moreover, this study is distinguished by its application to the cellular communications sector in Jordan. It also highlights the practical importance of the study in contributing to its recommendations in activating the role of transformational leadership in the cellular communications sector in Jordan and the use of its various axes in crisis management. It will also encourage managers to search for unconventional leadership patterns to apply in Jordan's cellular communications sector. 


\section{Literature Review}

\subsection{Transformational Leadership}

Leadership is the process that influences subordinates' behavior to motivate them to work and with a desire to accomplish and achieve the set goals (Schermerhorn, 2002).

Leadership was defined as the process of influencing the behavior of groups and directing them towards achieving the desired goals (Robbins, 2003).

Buchanan and Huczynski (2004) described leadership as the process of controlling the activities of the organized group in its efforts to set and achieve the organization's goals.

Transformational leadership is also defined as influencing significant changes in the attitudes and assumptions of the organization's members and building commitment to the organization's mission, goals, and strategies (Shin \& Zhou, 2003).

The characteristics of a transformational leader are summarized as follows (Crawford \& Strohkirch, 2002):

1-Creating a clear vision: One of the essential skills that characterize the leaders of organizations is to create a clear future vision and the ability to convey this vision and clarify it to the workers of the organization in order to create sufficient awareness for them and build mutual trust between them, which leads to the realization of this vision by subordinates (Johnson, 1998).

2-A good example: the transformational leader influences the followers by playing the role of a good example, and has committed themselves to be specific and critical administrative practices that contribute to establishing significant organizational development and serve as a good example for followers to follow. What is new for leaders is to inspire followers to take the right positions and commit to learning to meet challenges.

3-Enhancing employee acceptance of goals: Developed organizations seek to bring about the necessary change through their development. Therefore, it is necessary to encourage these workers to adopt learning objectives, and for this, transformational leaders must have the characteristics that support the goals adopted by the organization's workers and affect their choices. It ultimately leads to the existence of the learning organization (Coad \& Berry, 1998).

4-Mental support: One of the roles that leaders play in the organization is openness towards workers and encouraging them in order to take the leader as the ideal, by asking them questions that act as a catalyst for them and work to raise their curiosity, in addition to the leader playing the role of the trainer To them and the advisor to them while providing the elements of motivation and the necessary resources for the learning process, and this task is considered the responsibility of the leaders to build the progressive organization, and the workers include their responsibility to develop their capabilities in order to deeply understand the complex developments and developments regarding their jobs (Prewitt, 2003).

5-Mental stimulation: The pioneers of technological innovation are people who take risks by imposing their vision emanating from their inherent strength in innovation and creativity to achieve high quality in goods and services. Therefore, the challenge of the status quo in the organization and the aspiration for new means to improve learning and increase capacity To satisfy the needs and desires of customers; It is one of the highest values in the organization, and the role of transformational leadership in this field is to provide the vision and energy necessary for effective management of knowledge in the organization and its dissemination among employees, with a focus on creative and innovative methods in terms of technical aspects of modern workplaces. Leaders are also responsible for adopting the mission of nurturing and promoting learning in the organization in terms of empowering workers to understand the complexities in the surrounding work environment and strive to solve them through creative thinking, which in turn pushes them to search for new knowledge to carry out their tasks to achieve the higher goals of the organization (Politis, 2002).

\subsection{Dimensions of Transformational Leadership}

The Ideal Effect: that the leader instilled pride in the hearts of the followers, in a way that makes them exceed their interest to the good of the organization, and his constant emphasis on the collective mission (Bass, 2008).

Inspirational Stimulation: The leader speaks optimistically about the future, clarifies a clear vision for the future, and expresses confidence that goals will be achieved, which encourages team spirit and general enthusiasm (Bass, 2008).

Intellectual Simulation: The leader endeavors to hear different viewpoints, encourage unconventional thinking, and reconsider critical assumptions (Bass, 2008). 
Individual considerations: It can be defined as the leader's promotion of self-development, his treatment of team members as individuals, his identification of the different needs, abilities, and aspirations of team members, listening to the concerns of others, and helping them develop their strengths (Bass, 2008).

\subsection{Crisis Management}

Any organizational crisis can threaten the organization's goals and have profound effects on its relationships with stakeholders. Sakarneh $(2015,22)$ defined the crisis as "a set of sudden circumstances and events that involve a clear threat to the current stable situation in the nature of things, which is the critical point, and the decisive moment at which the fate of a development is determined, either for the better or for the worse."

In turn, it requires successful management of the crisis to get out of it with the least possible adverse effects. Crisis management contributes to enhancing an organization's ability to interact flexibly and quickly with various crisis forms. The purpose of organizational crisis management is to make timely decisions based on the best facts. (Aljuhmani \& Emeagwali, 2017, 50)

Hence, crisis management can be defined as "the process that consists of a set of ordered levels, which departments must go through when dealing with crisis events, starting from the perception of the events until the end of them" (Al-Qatawneh, 2012, 224)

Crisis management was also defined as a set of activities and communications carried out by managers in order to reduce the likelihood of the occurrence of the crisis, and to reduce the negative effects of the crises that occurred in addition to the efforts put in place to restore the system after the end of the crisis. (Bundy, Pfarrer, \& Coombs, 2017, 1663)

Jafar $(2017,301)$ defined it as "the process of pre-planning for an unexpected negative event to limit or reduce its harm to the organization by developing strategies or a set of scenarios expected to occur and proposing appropriate solutions for each of them in the event that it occurs."

According to Mitroff \& Alpaslan (2003), crises are divided into ordinary and extraordinary crises, while Cutlip, et al. (2006). They are divided into eight types: (natural, technological, confrontational, malicious, perverse administrative values, deception, mismanagement, and business and economics.

Previous studies from all studies related to crisis management recommended the need to address and the ultimate purpose appears to address the crisis as effectively and quickly as possible. Because if the crisis remains unresolved, it will become at the top of the list of media outlets and broadcasting and propaganda from companies, which exacerbates it due to the difficulty of solving it (Khodarahmi, 2009).

Most crises go through five basic stages:

- Early warning level: which relates to the detection and analysis of indicators that predict the possibility of a crisis. (Frandsen \& Johansen, 2017)

- The level of preparedness and prevention: providing the material and human resources necessary to avoid the occurrence of the crisis and develop scenarios to confront its effects. (Sacarneh, 2015, 139)

- The level of damage containment: It is related to counting the negative effects of a crisis after its occurrence as a result of the failure of measures to avoid it. (Davor, et al., 2018)

- Level of recovery activity: which relates to the organization's return to conducting its business through programs that were established prior to the occurrence of the crisis (Holmgren, 2015)

- Level of learning: which relates to the level of benefit from lessons and lessons from what happened in the crisis and assessing the existing situation. (Mikusova \& Horvathova, 2019)

\section{Hypotheses of the Study}

Ho: There is no statistically significant impact at $(\alpha \leq 0.05)$ for transformational leadership with its dimensions (ideal effect, inspirational stimulation, intellectual stimulation, individual considerations) on crisis management in the cellular communications sector in Jordan.

The main hypothesis has been divided into the following sub-hypotheses:

Ho.1: There is no statistically significant impact at $(\alpha \leq 0.05)$ for the ideal effect on crisis management in Jordan's cellular communications sector.

Ho.2: There is no statistically significant impact at the level of $(\alpha \leq 0.05)$ for the inspirational stimulation in crisis management in Jordan's cellular communications sector. 
Ho.3: There is no statistically significant impact at $(\alpha \leq 0.05)$ for intellectual stimulation in crisis management in Jordan's cellular communications sector.

Ho.4: There is no statistically significant impact at $(\alpha \leq 0.05)$ for individual considerations in crisis management in Jordan's cellular communications sector.

\section{Research Methodology}

This study relies on the descriptive and analytical approach for this study to identify the impact of transformational leadership in crisis management.

\section{Study population:}

The study population includes administrators working in Zain, Orange, and Umniah companies.

\section{Study sample:}

A Convenience non-probability sample of 100 managers was taken to distribute the study questionnaire to them.

\section{Study tools:}

Primary sources: It relates to the survey questionnaire designed to collect the study data.

Secondary sources: It relates to books and previous studies related to the subject of study.

\section{Results}

\section{Sample Characteristics:}

Frequency and percent is used to describe the sample characteristics, it is found the $80 \%$ of the sample is males, $50 \%$ of the sample has Bachelor Degree, whereas $68 \%$ of the sample has experience for more than 15 years.

\section{Reliability test:}

Cronbach Alpha is used to test the reliability of the questionnaire, it is found that the alpha value is equal to 0.956 which is good because it is greater than the accepted percent 0.60 (Sekaran \& Bougie, 2010).

\section{Multicolleniarity test:}

The researchers conducted VIF and Tolerance tests to determine that the independent variables are not correlated. The following results were found:

Table 1. Multicolleniarity test

\begin{tabular}{lll}
\hline & Tolerance & VIF \\
\hline ideal effect & .233 & 4.284 \\
inspirational stimulation & .193 & 5.174 \\
intellectual stimulation & .223 & 4.491 \\
individual considerations & .391 & 2.561 \\
\hline
\end{tabular}

Table (1) indicates that the VIF value is less than 10 , and the Tolerance value is greater than 0.10 , indicating that there is no Multicolleniarity problem. (Gujarati \& Porter, 2009)

\section{Descriptive Analysis:}

Mean and standard deviation were used to describe attitudes toward the following variable:

Table 2. Descriptive Statistics

\begin{tabular}{llllll}
\hline & $\mathrm{N}$ & Minimum & Maximum & Mean & Std. Deviation \\
\hline ideal effect & 100 & 1.00 & 5.00 & 3.6900 & .98406 \\
inspirational stimulation & 100 & 1.00 & 5.00 & 3.9180 & 1.08287 \\
intellectual stimulation & 100 & 1.00 & 5.00 & 4.0540 & 1.24847 \\
individual considerations & 100 & 1.00 & 5.00 & 3.9540 & .92151 \\
crisis management & 100 & 1.00 & 5.00 & 4.1200 & 1.09618
\end{tabular}

Table 2 shows positive attitudes toward the above hypothesis since their means are greater than the scale (3). Also, it is found that (intellectual stimulation) variable has the greatest mean comparing with (Ideal Effect), which has the lowest mean. 


\section{Hypothesis Testing:}

Ho: There is no statistically significant impact at $(\alpha \leq 0.05)$ for transformational leadership with its dimensions (ideal effect, inspirational stimulation, intellectual stimulation, individual considerations) on crisis management in the cellular communications sector in Jordan.

Multiple regression is used to test the above hypothesis, the following results are found:

Table 3. Hypothesis testing

\begin{tabular}{lllll}
\hline & & \multicolumn{3}{c}{ Model Summary } \\
\hline Model & $\mathrm{R}$ & R Square & Adjusted R Square & Std. Error of the Estimate \\
1 & $.962^{\mathrm{a}}$ & .925 & .922 & .30673 \\
a. Predictors: (Constant), individual considerations, intellectual stimulation, ideal effect, inspirational stimulation
\end{tabular}

\begin{tabular}{lllllll}
\hline & \multicolumn{5}{c}{ ANOVA $^{\mathbf{a}}$} \\
\hline Model & & Sum of Squares & df & Mean Square & F & Sig. \\
\hline 1 & Regression & 110.022 & 4 & 27.505 & 292.349 & $.000^{\text {b }}$ \\
& Residual & 8.938 & 95 & .094 & & \\
& Total & 118.960 & 99 & & &
\end{tabular}

a. Dependent Variable: crisis management

b. Predictors: (Constant), individual considerations, intellectual stimulation, ideal effect, inspirational stimulation

\begin{tabular}{|c|c|c|c|c|c|c|}
\hline \multicolumn{7}{|c|}{ Coefficients } \\
\hline & & \multicolumn{2}{|c|}{ Unstandardized Coefficients } & \multicolumn{2}{|c|}{ Standardized Coefficients } & \multirow[b]{2}{*}{ Sig. } \\
\hline \multicolumn{2}{|c|}{ Model } & B & Std. Error & Beta & $\mathrm{t}$ & \\
\hline \multirow[t]{5}{*}{1} & (Constant) & -.016 & .138 & & -.115 & .908 \\
\hline & ideal effect & .595 & .065 & .534 & 9.174 & .000 \\
\hline & inspirational stimulation & .223 & .065 & .220 & 3.446 & .001 \\
\hline & intellectual stimulation & .515 & .052 & .586 & 9.832 & .000 \\
\hline & individual considerations & .852 & .054 & .717 & 15.924 & .000 \\
\hline
\end{tabular}

a. Dependent Variable: crisis management

It is found that $\mathrm{F}$ value $=292.349$ is significant at 0.05 level that means there is a statistically significant impact at $(\alpha \leq 0.05)$ for transformational leadership with its dimensions (ideal effect, inspirational stimulation, intellectual stimulation, individual considerations) on crisis management in the cellular communications sector in Jordan.

Also, $r=0.962$ reflects a high level of correlation between the independent variables and dependent variable also the independent variables explain $92.5 \%$ of the variance in the deponent variable.

The main hypothesis has been divided into the following sub-hypotheses:

Ho.1: There is no statistically significant impact at $(\alpha \leq 0.05)$ for the ideal effect on crisis management in Jordan's cellular communications sector.

The table of Coefficients shows that $\mathrm{t}$ value $=9.174$ is significant at $(\alpha \leq 0.05)$, and Beta value $=0.534$ reflects a moderate relationship between the independent variable and the dependent variable. That means there is a statistically significant impact at $(\alpha \leq 0.05)$ for the ideal effect on crisis management in Jordan's cellular communications sector.

Ho.2: There is no statistically significant impact at the level of $(\alpha \leq 0.05)$ for the inspirational stimulation in crisis management in Jordan's cellular communications sector.

The table of Coefficients shows that $t$ value $=3.446$ is significant at $(\alpha \leq 0.05)$ and that Beta value $=0.22$ reflects a low relationship between the independent and dependent variables. That means there is a statistically significant 
impact at the level of $(\alpha \leq 0.05)$ for the inspirational stimulation in crisis management in Jordan's cellular communications sector.

Ho.3: There is no statistically significant impact at $(\alpha \leq 0.05)$ for intellectual stimulation in crisis management in Jordan's cellular communications sector.

The table of Coefficients shows that $\mathrm{t}$ value $=9.832$ is significant at $(\alpha \leq 0.05)$ and Beta value $=0.586$ reflects a medium relationship between the independent variable and the dependent variable. That means there is a statistically significant impact at $(\alpha \leq 0.05)$ for intellectual stimulation in crisis management in Jordan's cellular communications sector.

Ho.4: There is no statistically significant impact at $(\alpha \leq 0.05)$ for individual considerations in crisis management in Jordan's cellular communications sector.

The table of Coefficients shows that $t$ value $=15.924$ is significant at $(\alpha \leq 0.05)$ and Beta value $=0.717$ reflects a high relationship between the independent variable and the dependent variable. That means there is a statistically significant impact at $(\alpha \leq 0.05)$ for individual considerations in crisis management in Jordan's cellular communications sector.

\section{Conclusion and Recommendations}

This study aimed to identify the impact of transformational leadership on crisis management in the Cellular Communications sector in Jordan.

It was found that the following fields are the most prominent points agreed upon by the sample members in terms of managing crises in organizations: senior management should respond quickly to the emerging changes that occur in the organization's environment in a way that helps it predict crises.

Senior management should provide training to employees on the application of alternative solutions Maintaining the security and confidentiality of information in the systems used during the handling of the crisis reduces the risks of the crisis, and the higher management works to create a state of reassurance among the employees after overcoming the crisis stage. The senior management evaluates previous plans to develop and improve them in order to deal with future crises.

The researcher suggests different recommendations, such as the necessity for the administration to use the information network security system to retrieve information before the crisis occurs. It is essential to update the information systems used in the organization to store the crises' results and facilitate their retrieval when needed. Senior management necessity to benefit from its previous experiences to generate knowledge benefits the organization's employees. The necessity for working on forming work teams with diverse experiences to exchange knowledge among them. The need for senior management to create an organizational culture that promotes the useful application of knowledge.

\section{References}

Aljuhmani, H., \& Emeagwali, O. (2017). The Roles of Strategic Planning in Organizational Crisis Management: The Case of Jordanian Banking Sector. International Review of Management and Marketing, 7(3), 50-60.

Al-Qatawneh, A. (2012). The Impact of the Crisis Management System on the Organizational Climate in Jordanian Commercial Banks, "A Field Study" from the Managers' Point of View. Jordan Journal of Business Administration, 8(2), 221-235.

Bass, M., \& Ruth, B. (2008). The Bass Handbook of Leadership: Theory, Research, and Managerial Applications. New York: Free.

Bundy, J., Pfarrer, M., \& Coombs, W. (2017). Crises and Crisis Management: Integration, Interpretation, and Research Development. Journal of Management, 43(6), 1661-1692. https://doi.org/10.1177/0149206316680030

Coad, A., \& Berry, A. (1998). Transformational leadership and learning orientation. Leadership \& Organization Development Journal, 19, 164-172. https://doi.org/10.1108/01437739810210211

Crawford, C. B., \& Strohkirch, C. S. (2002). Leadership education and management of knowledge organizations: an overview. Journal of Leadership Education, 1(2), 18-33. https://doi.org/10.12806/V1/I2/RF2

Cutlip, S. M., Center, A. H., \& Broom, G. M. (2006). Effective Public Relations, 9th ed., Pearson Education International, Upper Saddle River, NJ. 
Davor, L., Andrijana, P., \& Julija, P. (2018). Evolving Crisis Management: Current Jobs and Required Employee's Skills and Characteristics Analysis. University of Zagreb, Faculty of Economics and Business, Zagreb, Croatia, pp. 524-582.

Frandsen, F., \& Johansen, W. (2017). Organizational crisis communication: A multivocal approach. London: Sage.

Holmegren, F., \& Johansson, R. (2015). Crisis Management-The nature of managing crises. unpublished master's thesis in business administration. Jönköping International Business School, Jönköping university.

Jafar, Yunus. (2017). The Impact of Strategic Planning on Crisis Management An Empirical Study: Public Institutions in the Jerusalem Suburbs District. Al-Aqsa University Journal (Human Sciences Series), 21(1), 293-324. https://doi.org/10.12816/0038379

Johnson, R. (1998). Embracing change: a leadership model for the learning organization. International Journal of Training and Development, 2(2), 141-150. https://doi.org/10.1111/1468-2419.00042

Khodarahmi, E. (2009). Crisis management. Disaster Prevention and Management, 18(5), 523-528. https://doi.org/10.1108/09653560911003714

Mikusova, M., \& Horvathova, P. (2019). Prepared for a crisis? Basic elements of crisis management in an $\begin{array}{lllll}\text { organization. } & \text { Economic } & \text { Research }\end{array}$ https://doi.org/10.1080/1331677X.2019.1640625

Mitroff, I., \& Alpaslan, M. C. (2003). Preparing for evil. Harvard Business Review, 81(4), 109-115.

Nemanich, L., \& Keller, R. (2007). Transformational leadership in acquisituion: A field study of employees. Leadership Quarterly, 18(1), 49-68. https://doi.org/10.1016/j.leaqua.2006.11.003

Politis, J. (2002). Transformational and transactional leadership enabling (disabling) knowledge acquisition of self managed teams: the consequences for performance. Leadership and Organization Development Journal, 3(4), 186-197. https://doi.org/10.1108/01437730210429052

Prewitt, V. (2003). Leadership development for learning organizations. Leadership and Organization Development Journal, 24(2), 58-61. https://doi.org/10.1108/01437730310463242

Sakarneh, Bilal. (2015). Crisis Management. Jordan: Dar Almaseerah for Publishing, Distribution and Printing.

Sekaran, U., \& Bougie, R. (2010). Research methods for business: A skill building approach. John Wiley \& Sons.

Shin, S., \& Zhou, J. (2003). Transformational Leadership, Conservation, and Creativity: Evidence from Korea. Academy of Management Journal, 46(6), 703-714. https://doi.org/10.5465/30040662

Tekin, Ö. (2014). Importance of Crises Management for Public Administration: The Practice in TURKISH Public Administration, the 2014 WEI International Academic Conference Proceedings Budapest, Hungary.

\section{Copyrights}

Copyright for this article is retained by the author(s), with first publication rights granted to the journal.

This is an open-access article distributed under the terms and conditions of the Creative Commons Attribution license (http://creativecommons.org/licenses/by/4.0/). 